\title{
\begin{tabular}{l|l} 
Wolters Kluwer & Lippincott Williams \& Wilkins \\
Heath
\end{tabular}
}

emEditorial
Manager

\section{Tutorial for Reviewers}

\author{
Need more help submitting Reviews to Editorial Manager? \\ Read the LWW Guide for Reviewers
}

Search the Online Knowledge Base

This document is the confidential and proprietary information of Aries Systems Corporation, and may not be disseminated or copied without the express written permission of Aries Systems Corporation. The information contained in this document is tentative, and is provided solely for planning purposes of the recipient. The features described for this software release are likely to change before the release design and content are finalized. Aries Systems Corporation assumes no liability or responsibility for decisions made by third parties based upon the contents of this document, and shall in no way be bound to performance therefore. Editorial Manager is a registered trademark and the property of Aries Systems Corporation. 


\section{LWW Editorial Manager ${ }^{\circledR}$ - Tutorial for Reviewers}

\section{Table of Contents}

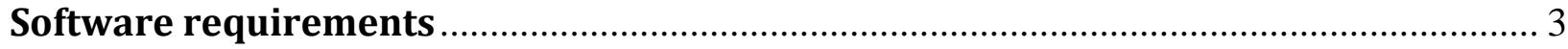

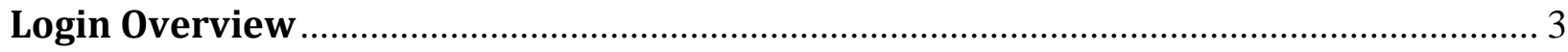

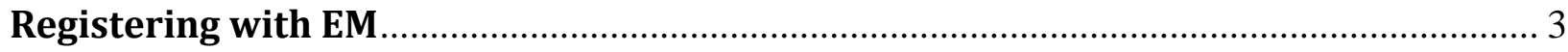

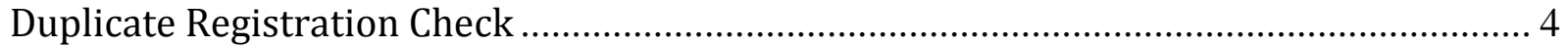

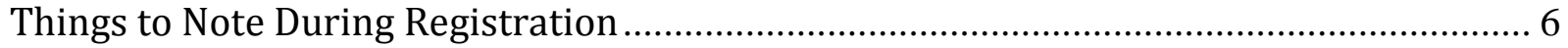

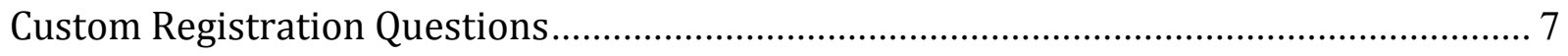

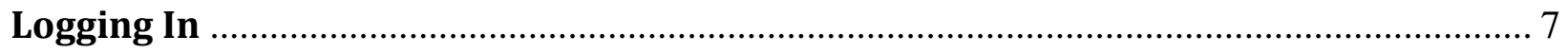

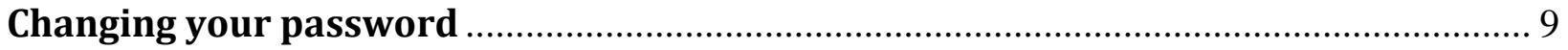

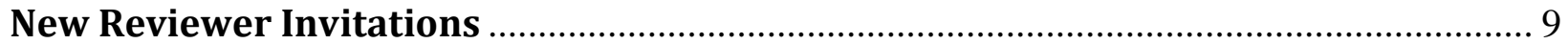

Responding to an Invitation by Logging into Editorial Manager .................................... 10

Responding to an invitation using the Deep Links in the invitation e-mail ...................... 11

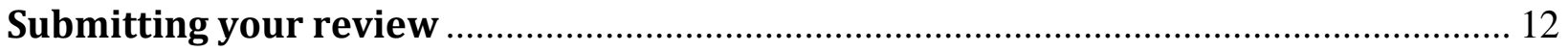

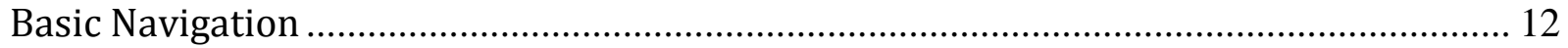

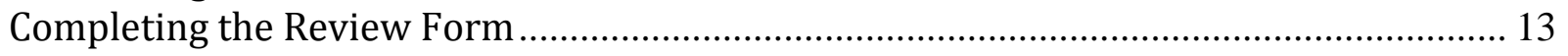

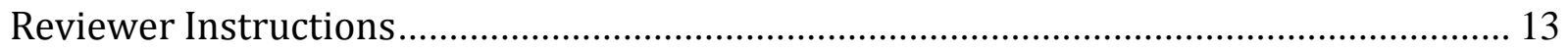

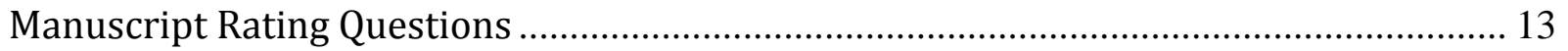

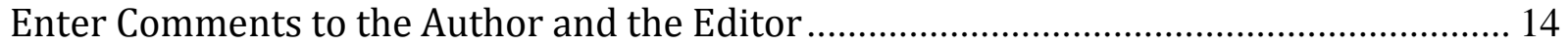

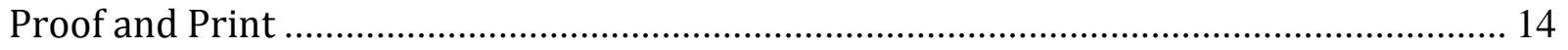

Submit the Review ............................................................................................... 14

Revised Submissions: Viewing an Author's Response to Reviewers .......................... 15 


\section{LWW Editorial Manager ${ }^{\circledR}$ - Tutorial for Reviewers}

\section{Software requirements}

As a Reviewer using Editorial Manager, you must have Adobe Acrobat Reader (a PDF reader) installed on your system. If you need to install this software, you can download the free Adobe Acrobat Reader at the following address: http://www.adobe.com/products/acrobat/readstep2.html

If you experience difficulty installing or utilizing this software, you should contact your IT department for assistance. Adobe also offers a help database for their free Reader at this address:

http://www.adobe.com/support/products/acrreader.html

For general Software and Hardware requirements when using EM, please use the following link:

http://www.editorialmanager.com/homepage/homefaq10.html

\section{Login Overview}

When an Editor invites a Reviewer to review a submission, the Editor is given the option to 'Proxy Register' them if they are not already registered in their Journal's EM site. This can be done by giving the minimum information of 'First Name', 'Last Name' and 'E-mail Address'. If you have been proxy registered, you may receive an e-mail detailing this username and password. You may also receive an e-mail inviting you to Review a paper. There will be links pointing you to the Journal site and to the paper that you have been invited to review. You can choose to Accept or Decline the invitation.

Following a proxy register, the first time you log in to the system, you will be prompted to enter more information.

\section{Registering with EM}

Things to Remember:

- If you received an invitation to review a paper from a Journal using EM, then you do not need to register with the system.

- Registering with a Journal EM system will provide you the ability to submit manuscripts as an author.

- If you register with the Journal's EM system, that does not mean you will automatically be assigned reviews by the editors. In order to ensure becoming a reviewer for a journal, you will need to write to the journal office and formally offer your services. If the Journal accepts, you will be given reviewer login privileges and may begin to receive assignments from the editors.

If you choose to register with the Journal's EM system, please visit the EM site. From the main navigation menu at the top of the Journal site's Welcome screen you will see a set of menu options. Click on 'REGISTER'. 


\section{LWW Editorial Manager ${ }^{\circledR}$ - Tutorial for Reviewers}

\section{emEditorial Manager}

HOME - LOGIN * HELP - REGISTER * UPDATE MY INFORMATION • JOURNAL OVERVIEW

MAIN MENU * CONTAGT US * SUBMIT A MANUSCRIPT * INSTRUCTIONS FORAUTHORS

Once you click 'Register' the following screen will be displayed:

PRE-

REGISTRATION

PAGE

To register to use the Editorial Manager system, please enter the requested information. Upon successful registration, you will be sent an e-mail with registration.

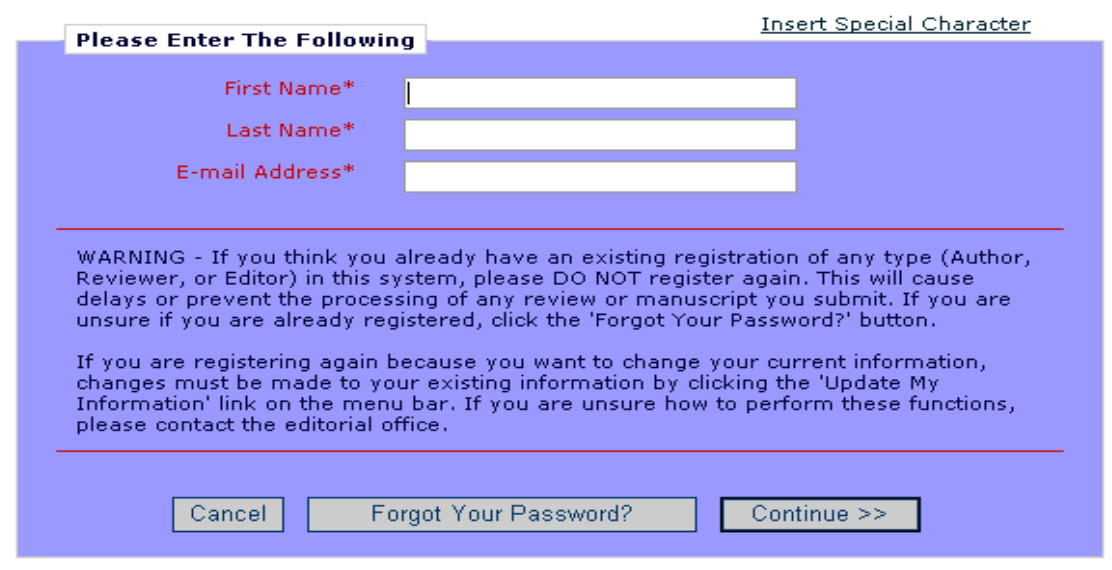

\section{Duplicate Registration Check}

EM will be able to check whether you are already registered once you have entered your First Name, Last Name and E-mail Address. Click on the button labeled 'Continue'. This will execute a search of the database for a duplicate record.

If no duplicate matches are found in the database - then you will be allowed to proceed to the second step, the Registration process. The following screens will be displayed: 


\section{LWW Editorial Manager ${ }^{\circledR}$ - Tutorial for Reviewers}

\section{REGISTRATION PAGE}

Welcome to the Journal of Wendy Moore

We are happy to offer our contributors the opportunity to submit their papers online using Editorial Manager $[\mathbb{E}$.

The following information will guide you through the Editorial Manager@ system. Instructions and information about using this system and FAQs for Authors and Reviewers are available in the HELP section.

If you are still having difficulty, contact Wendy Moore - Journal Adfice Aminstrator (whoored

Reations will be be addressed in the order received.

Upon successful registration, you will be sent an e-mail with instructions to verify your registration.

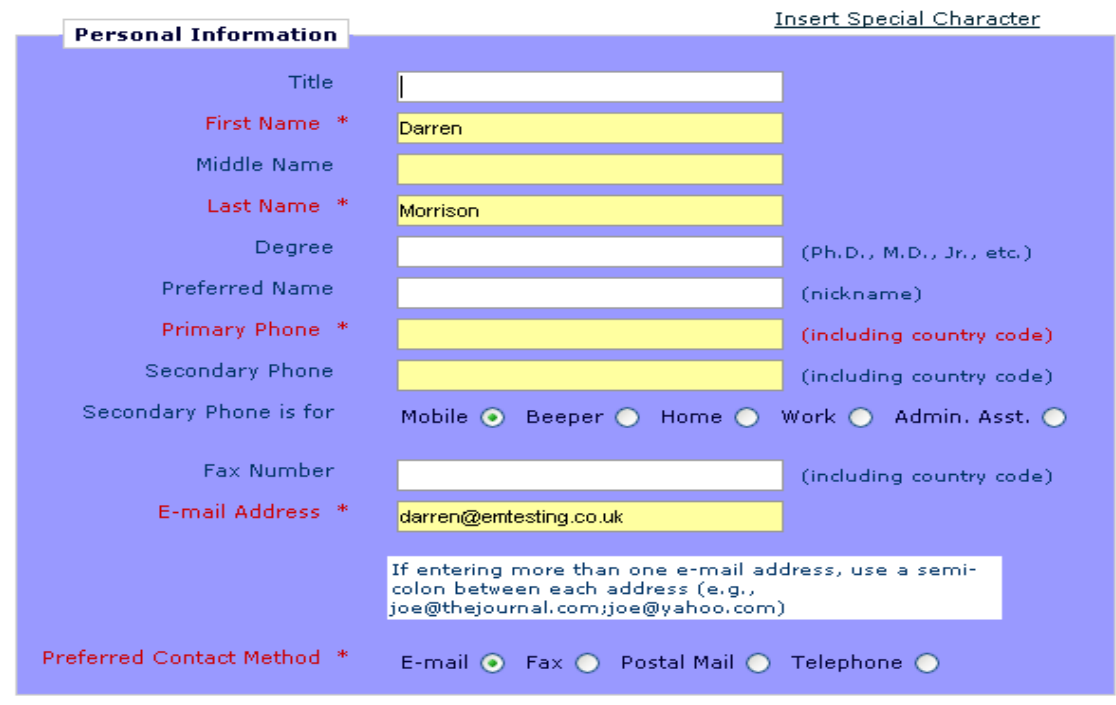

Institution Related Information

IIser special Mllar alter

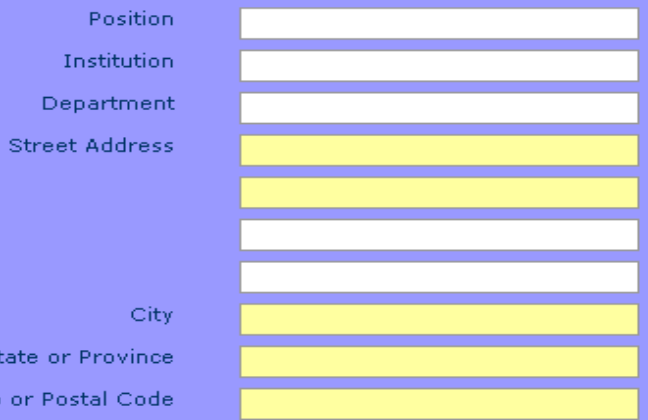

Country *

Please choose a country

Address is for *

Available as a Reviewer?

Yes $O$ No $\odot$

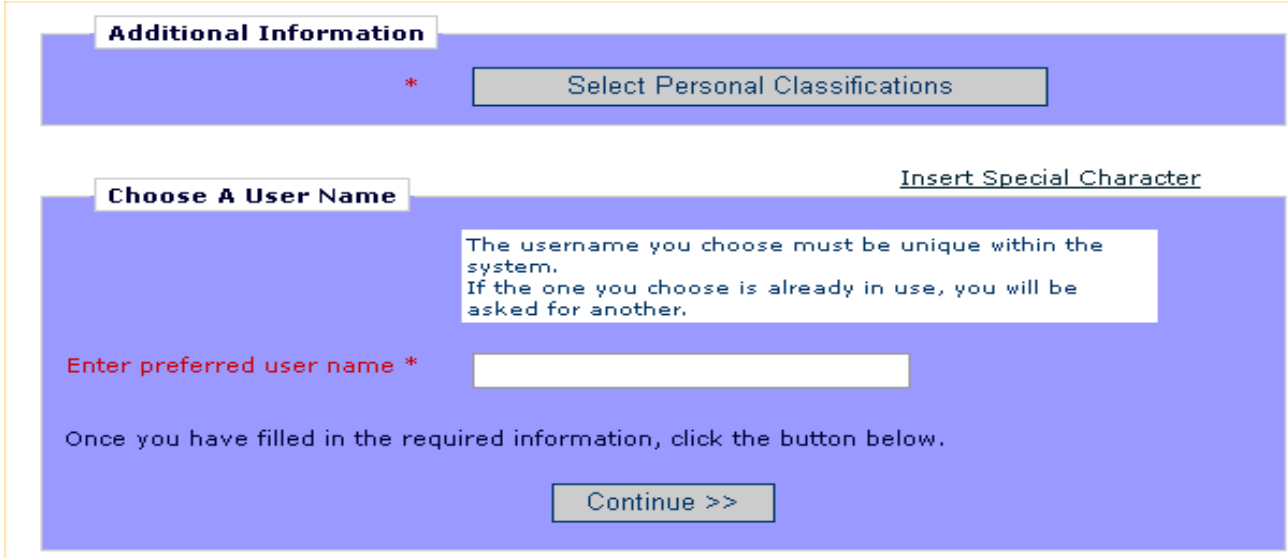

Confidential - Subject to change - Copyright @ 2013, Aries Systems Corporation - Page 5 


\section{LWW Editorial Manager ${ }^{\circledast}$ - Tutorial for Reviewers}

Note: Information fields marked with asterisks $(*)$ cannot be left empty.

\section{Things to Note During Registration}

- Multiple E-mail Address Request - A new SPAM information warning next to the email address field, strongly urges users to enter a second e-mail address. If, for some reason, the system e-mails get caught in a SPAM filter for one e-mail address, you should receive the e-mail at a secondary e-mail address from a different service provider (e.g. Yahoo, AOL, etc.).

- If you want the Journal to be able to select you as a Reviewer, you can set the Option "Are you available as a Reviewer?" to 'Yes'.

- If the Journal is using classifications, you may also select your own personal classifications from their pre-defined list.

- At the bottom of the form you must enter a preferred username. Failure to enter a username or any other required information for your registration will result in the display of the following warning:

ERROR NOTICE

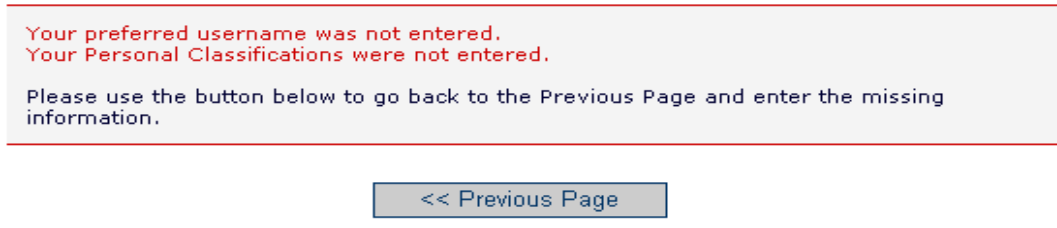

Note: You must remember this username in order to access the Journal's EM System.

When you are satisfied with the information you have provided, click the 'Continue >>' button at the bottom to proceed.

A "Registration Confirmation" page will appear, allowing you to double check that you've entered the correct information. Please take a good look to make sure everything is spelled correctly, and that your e-mail address is correct.

CONFIRM

REGISTRATION
Please confirm the following very important information:

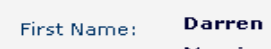

Last Name: Morrison

Username: Dazza

Email Address: darren@emtesting.co.uk

Country: BELGIUM

If any of the information above is incorrect, please click the 'Previous Page' button below to go back and make the necessary correction(s) and submit the form again.

If the information is correct and you wish to complete your registration, click the 'Continue' button below. 


\section{LWW Editorial Manager ${ }^{\circledR}$ - Tutorial for Reviewers}

If all fields are correct, click on 'Continue'. You have now completed the registration process, and may quit out of your browser to check your e-mail for the password that will be sent to you.

\section{Custom Registration Questions}

If the journal has opted to require that users respond to registration questions the following step will appear before you can complete the registration process. A box with an asterisk next to it indicates required information.

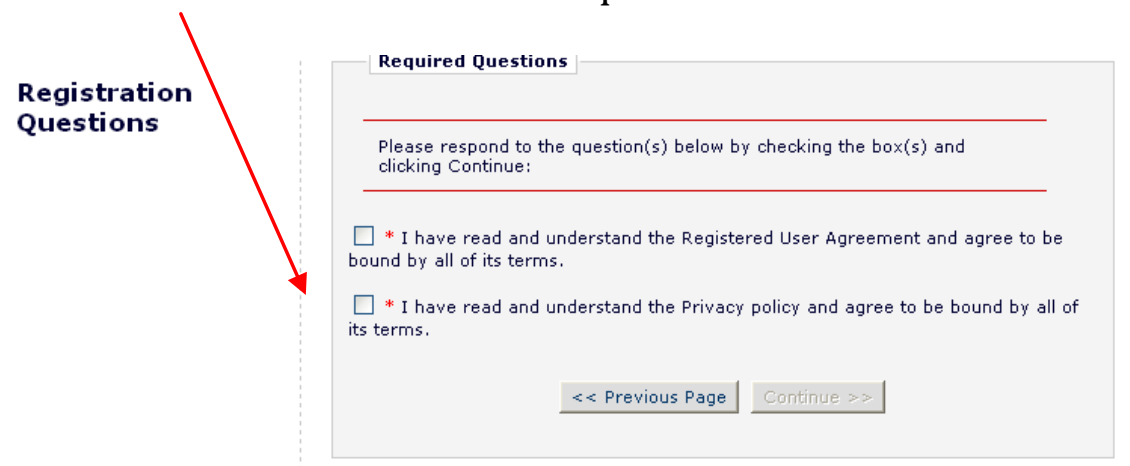

Once you have provided the journal with the necessary information, click on the Continue button to proceed.

\section{Logging In}

Once you have received a reviewer invitation from a journal or notification of your username and password following EM registration, you can start to use the system.

Go to the journal's EM website. From the main navigation menu at the top of the screen you will see a set of menu options. Click on 'LOGIN'- as shown below:

\section{emEditorial Manager"}

\section{HOME - LOGIN - HELP - REGISTER - UPDATE MY INFORMATION - JOURNAL OVERVIEW}

MAIN MENU - CONTAGT US - SUBMT A MANUSCRIPT - INSTRUCTIONS FORAUTHORS

The Editorial Manager Log-In screen (see below) will be displayed. Enter your username and password in the appropriate fields. If you have been asked to review a paper, you should click on the tab labeled 'Reviewer Login'. This will display the 'Reviewer Main Menu', which will contain a list of functions that you have been given permission to perform on the system. 


\section{LWW Editorial Manager ${ }^{\circledR}$ - Tutorial for Reviewers}

LOG-IN

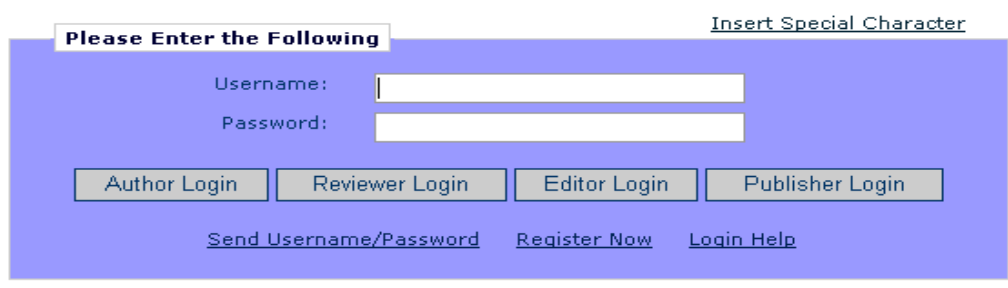

Software Copyright e 2005 Aries Systems Corporation.

Within EM there are 'ROLE' families to which users belong. Each role is given a set of permissions and a user can have multiple roles on the Journal.

REMEMBER: When a user is first registered they may, by default, belong to the 'AUTHOR' family. Some journals may have the default user role set to 'REVIEWER'. If you have been asked to review a paper, then click on the button labeled 'Reviewer Login'. However, if at any time in the future you want to submit a paper to the Journal, you would need to click on the button labeled 'Author Login'.

If the Journal has not allocated the REVIEWER role to your username, the following warning will appear:

LOG-IN ERROR

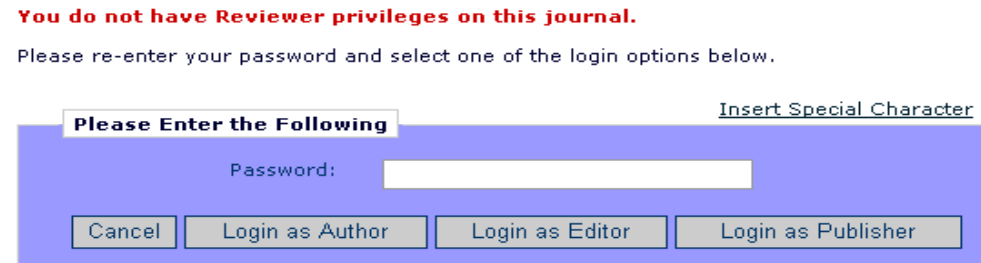

You will need to contact the Journal Office and request that they allocate this role to you.

Once you have successfully logged in, the Reviewer Main Menu will display any New Reviewer Invitations, Pending or Completed assignments that you may have - these links are also referred to as 'Folders'. The number of assignments you have within each folder will be displayed by the side of the entry.

\begin{tabular}{l|l}
$\begin{array}{l}\text { REVIEWER MAIN } \\
\text { MENU }\end{array}$ & Review Assignments \\
\hline & New Reviewer Invitations (2) \\
Pending Assianments (1) \\
Completed Assignments (1)
\end{tabular}




\section{LWW Editorial Manager ${ }^{\circledR}$ - Tutorial for Reviewers}

\section{Changing your password}

You may at any time change your password but you must first be logged in to the system. From the main navigation menu at the top of the screen (see below) select 'Update My Information'.

\section{emEditorial Manager"}

HOME - LOG OUT • HELP - REGISTER - UPDATE MY INFORMATION • JOURNAL OVERVIEW MAIN MENU - CONTACT US - SUBMT A MANUSCRIPT - INSTRUCTIONS FOR AUTHORS

The 'Update My Information' page dialog boxes will be displayed (see below).
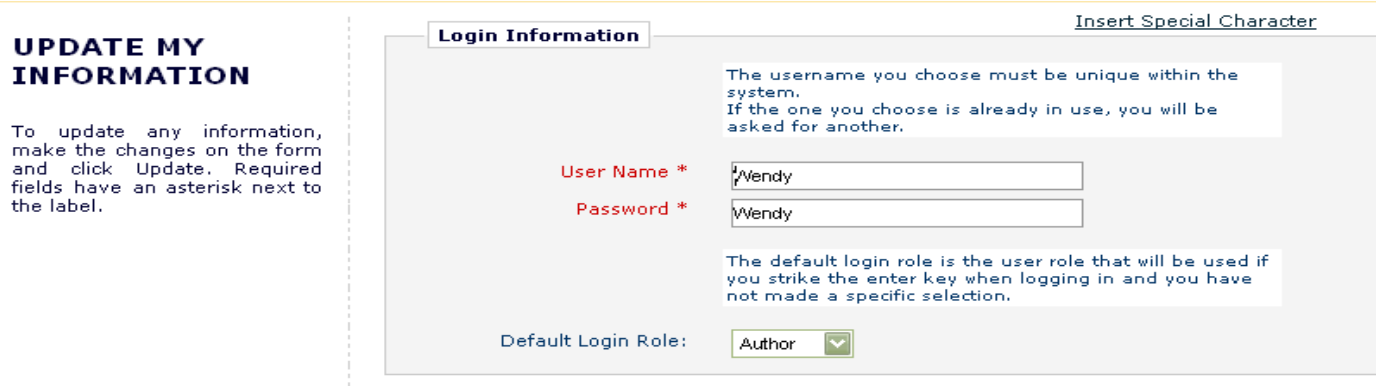

You will then be redirected to the Reviewer Registration screens where you may look at all of the information currently available about you to the Journal and update where applicable.

Once you have made your changes, click on the button labeled 'Submit'. EM will check to see if you have filled in all of the required fields - if you haven't, the following warning will be displayed:
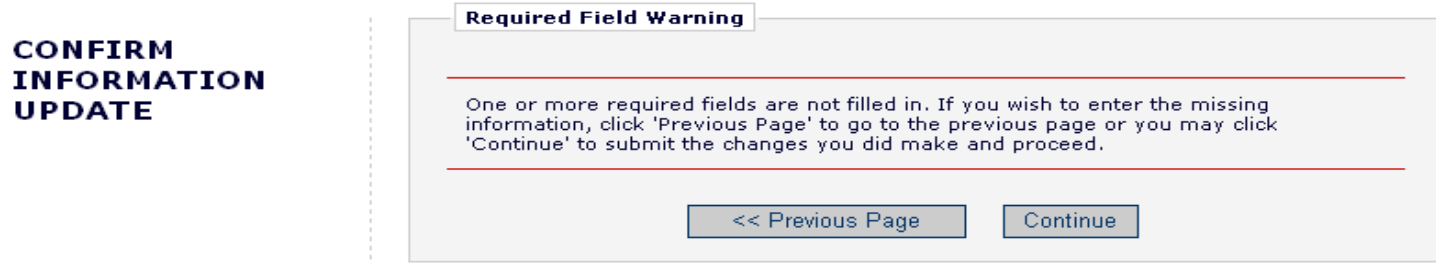

You have an option to return to your information pages (click on 'Previous Page' button), or you can just click on the button labeled 'Continue'.

\section{New Reviewer Invitations}

If you are chosen as a Reviewer for a manuscript, you will receive an e-mail from the Journal requesting your assistance. Before you can assess the manuscript, you must 


\section{LWW Editorial Manager ${ }^{\circledast}$ - Tutorial for Reviewers}

Clicking 'Decline to Review' will alert the Journal Office that you will not be reviewing the paper. The system will ask you to give the reason why you are unable to review and will also ask you to suggest other potential Reviewers.

DECLINE REVIEW

Please state a reason for declining to review Manuscript Number JowM-2005-15. Please suggest a colleague(s) qualified to review this paper.
Provide some information that will help us contact this person(s)

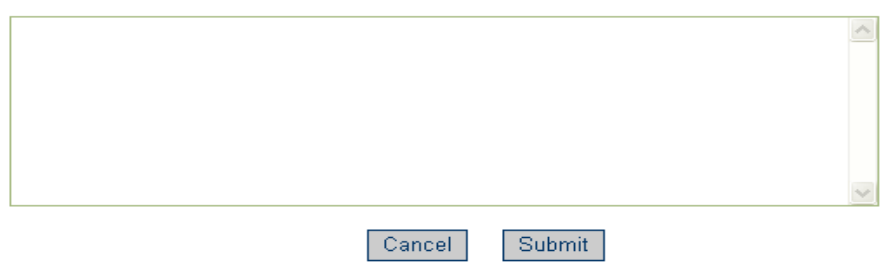

You will also be given confirmation that you have declined to review.

DECLINE REVIEW CONFIRMATION
Thank you for considering the invitation to review Manuscript Number JowM-

Your decision to decline has been forwarded to the journal.

Return to Main Menu

Responding to an invitation using the Deep Links in the invitation e-mail

Deep Links are hyperlinks that the Journal Office may include in any e-mail notification that they send or that are sent as part of the automated invitation element of EM. Clicking on the link will accept the invitation, decline the invitation, or allow you view the manuscript. Your browser will then automatically log you into EM and take you to the appropriate screen in EM where you will receive confirmation that your choice was received by the web site.

NOTE: In order for the links in the e-mail to work, you must NOT already be logged into EM.

- Accept a review invitation - The Reviewer will be able to click on the link to trigger the 'Agree to Review' function. If you 'Agree' to do the review assignment in this manner, you will be fully logged in and will be able to access the submission from the Main Menu.

- Decline a review invitation - The Reviewer will be able to click on the link to trigger the 'Decline to Review' function. If you 'Decline' the review assignment in this manner, you will still be delivered to the 'Decline to Review' page, where you will be asked to state a reason for declining the assignment and suggest other qualified Reviewers.

- View Reviewer version of the PDF - This link is available if the Journal Office configures their invitation e-mail to include it in the notification to you. Journals most often configure this link to appear in an email that is sent directly after a 


\section{LWW Editorial Manager ${ }^{\circledR}$ - Tutorial for Reviewers}

reviewer agrees to review a paper. The Reviewer will be able to click on the hyperlink to download the Reviewer version of the PDF.

\section{Submitting your review}

Once you've agreed to your review assignment, you can access the manuscript by clicking on 'Pending Assignments' on the Reviewer Main Menu as shown below.

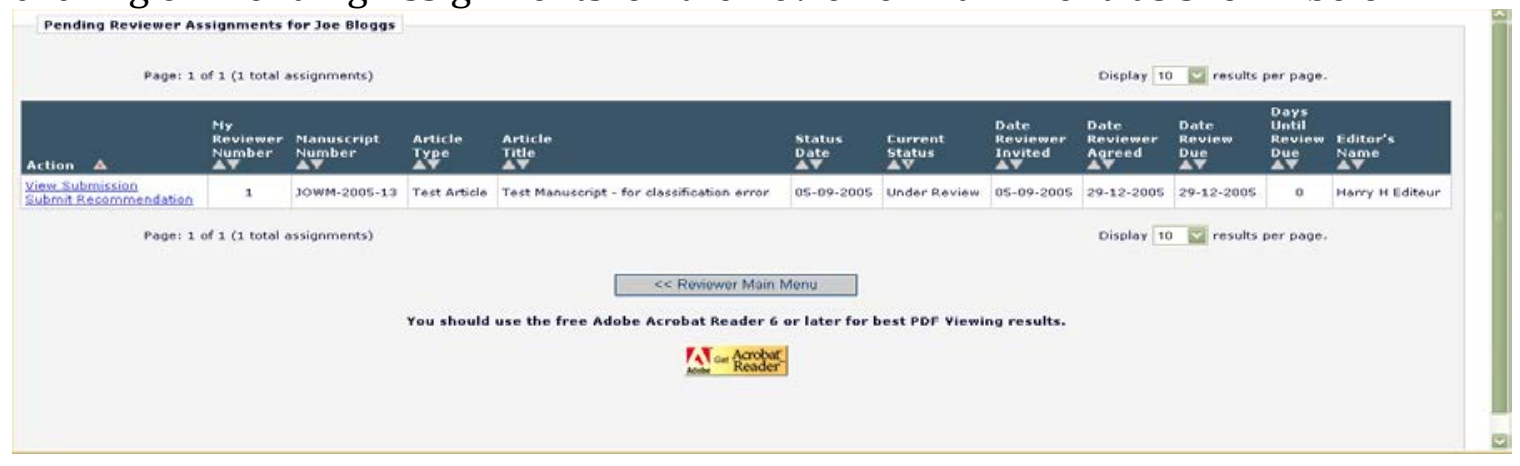

\section{Basic Navigation}

There are several actions you can perform from this menu:

- You may download the PDF of the manuscript to your desktop by clicking 'View Submission'. To print out a copy of the manuscript from the PDF file, select the 'File' menu in the upper left corner of the Acrobat window and select 'Print'.

- You may search the MEDLINE database to view articles that may be similar to a particular manuscript by using Similar Articles in MEDLINE. Clicking this link displays a new browser window featuring the Knowledge Finder@ MEDLINE search engine.

- Some Wolters Kluwer Health Journals provide an "Ovid - Title and Keywords" search. This feature allows direct searching of the Ovid Medline database. If you find that this service is missing and would like to search using Ovid, please contact your journal office to request configuration.

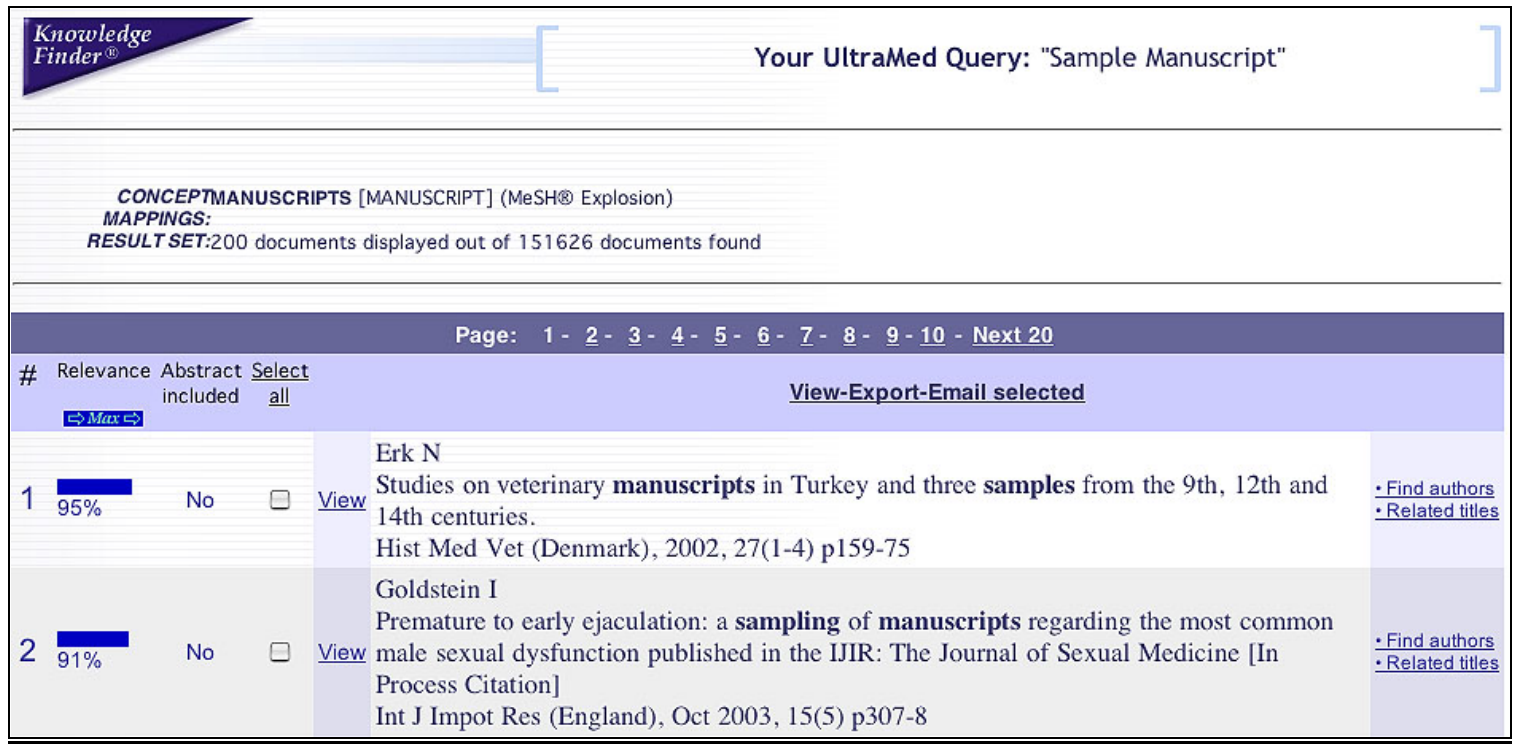




\section{LWW Editorial Manager ${ }^{\circledast}$ - Tutorial for Reviewers}

- When you are ready to submit your recommendation, click 'Submit Recommendation'. This will bring you to the 'Reviewer Recommendation and Comments' screen.

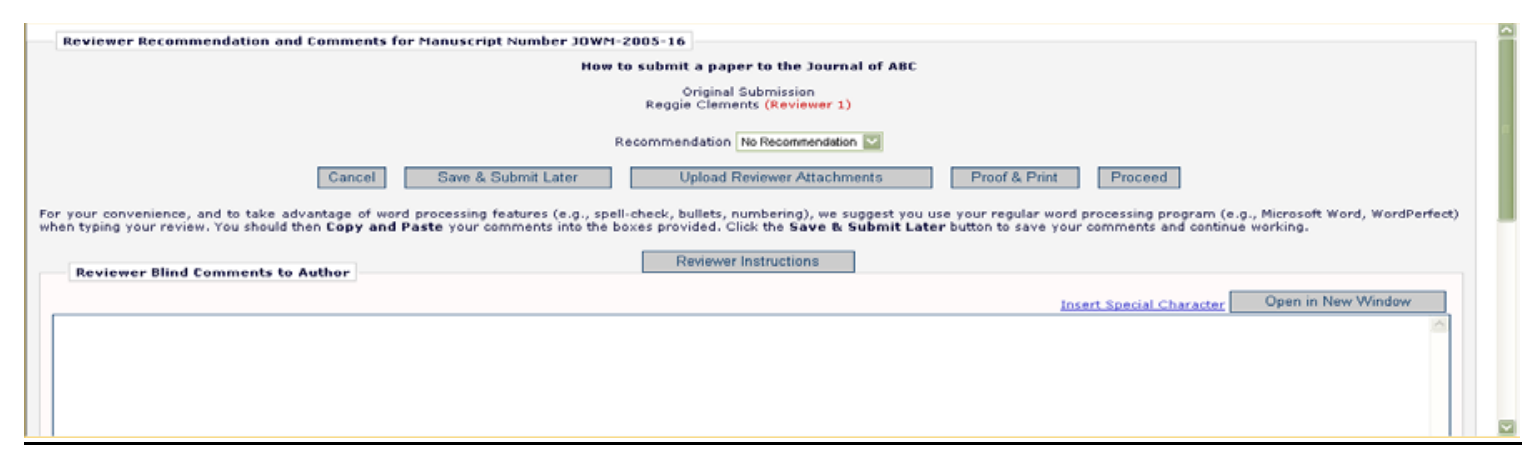

\section{Completing the Review Form}

To begin, please choose your recommendation term (Accept, Reject, Revise. etc.) via the pull-down form for 'Recommendation'.

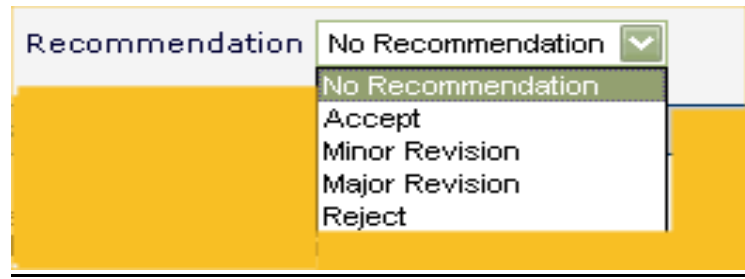

Reviewer Instructions

Each journal provides specific instructions for review of a submission - you can access these instructions by clicking the button labeled 'Reviewer Instructions' at the top of the review fields.

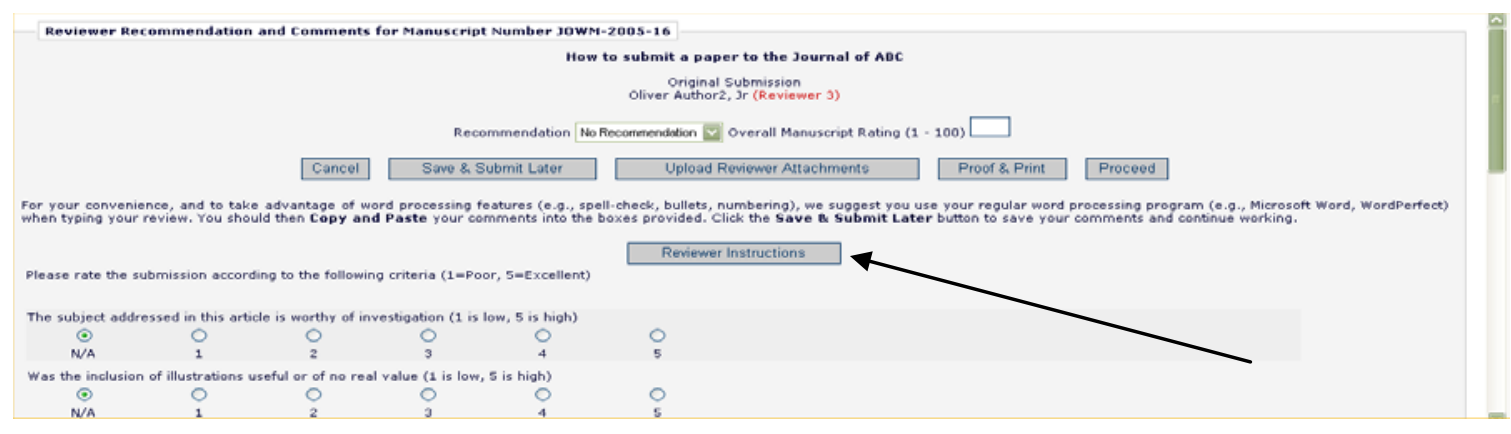

\section{Manuscript Rating Questions}

Reviewer forms are configured by the Journal Office, but you will typically be asked to answer Manuscript Rating Questions as shown below. These questions may appear at the beginning or end of the screen: 


\section{LWW Editorial Manager ${ }^{\circledR}$ - Tutorial for Reviewers}

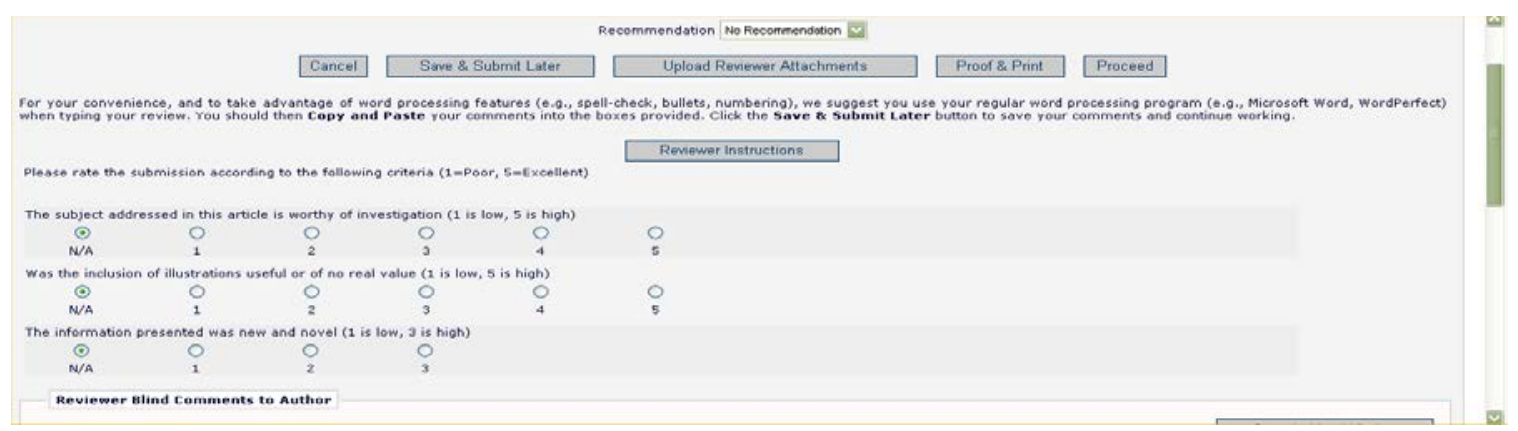

The journal can choose which questions to apply to each Article Type/Reviewer Role combination, and indicate whether each question is mandatory or optional. If the manuscript you are reviewing is a new, rather than revised submission, the Journal may also request that you assign an overall rating to the manuscript (1-100).

\section{Enter Comments to the Author and the Editor}

Enter your review comments to the Author and Editor in the fields provided. For your convenience you may use your regular word processing program (e.g., Microsoft Word, WordPerfect) when typing your review. You should then 'copy' and 'paste' your comments into the boxes provided. Click the 'Save \& Submit Later' button to save your comments and continue working. Clicking the 'Open in New Window' button at the top right of the data entry fields will open the field in a new browser window. This provides you with a larger view of the review field, which may make things simpler for you.

\section{Proof and Print}

Clicking 'Proof \& Print' will open a window containing all of the review information you have provided as a way for you to make a printout of your review for your records.

\section{$\underline{\text { Submit the Review }}$}

Click 'Submit Now' to proceed. This will bring up a screen that allows you to proofread before sending it to the Journal Office. If you need to make further edits, click 'Edit Review'. If you are satisfied with your review, click 'Submit Review to Journal Office'.

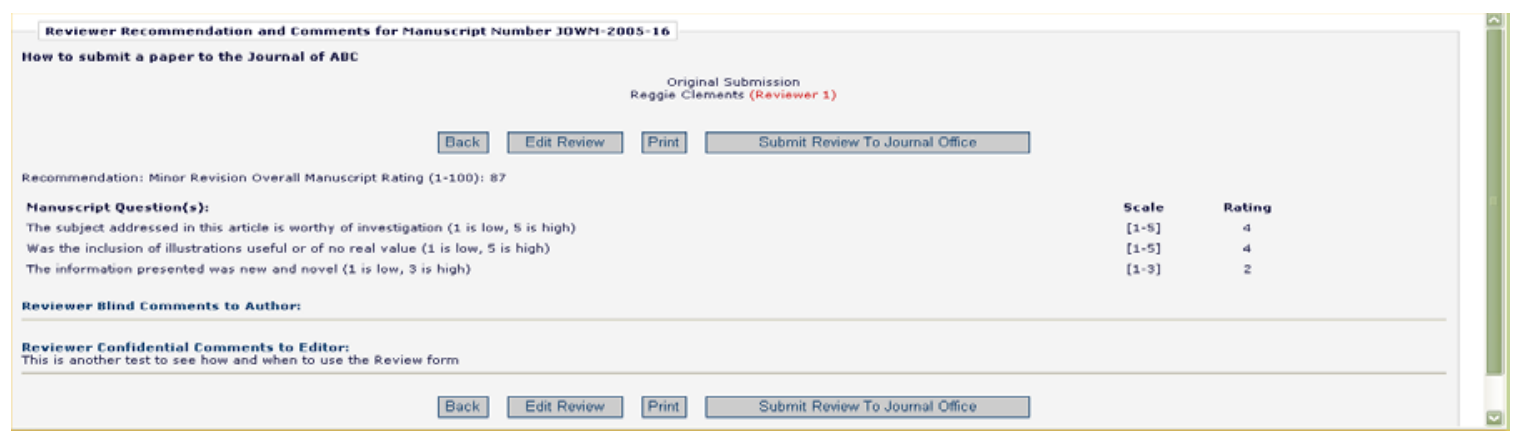

You are given a final opportunity to check your recommendation - click on OK to proceed or Cancel to make further changes. 


\section{LWW Editorial Manager ${ }^{\circledR}$ - Tutorial for Reviewers}

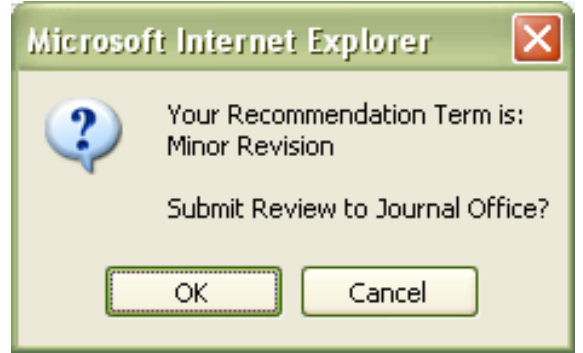

Once you have successfully submitted your review, you will receive a screen thanking you for your review with a button to take you back to your main menu.

Thank you for reviewing Manuscript Number JOWM-2005-16.

$<<$ Reviewer Main Menu

\section{Revised Submissions: Viewing an Author's Response to Reviewers}

Many journals require authors to build their response to reviewers into the revised submission PDF. All you need to do is click "View Submission" and locate the point-bypoint response to your prey\%ous comments. You may then decide whether or not the revision satisfies your previous requests and submit your new set of comments.

Alternately, some joyrnals will automate the response to the reviewers so you can access it by a hot-link outside of the submission PDF. If the journal has made this a required or optional step of the process for a submission of a revision, then you will see the following link when you log-in to begin your review of the revised submission:

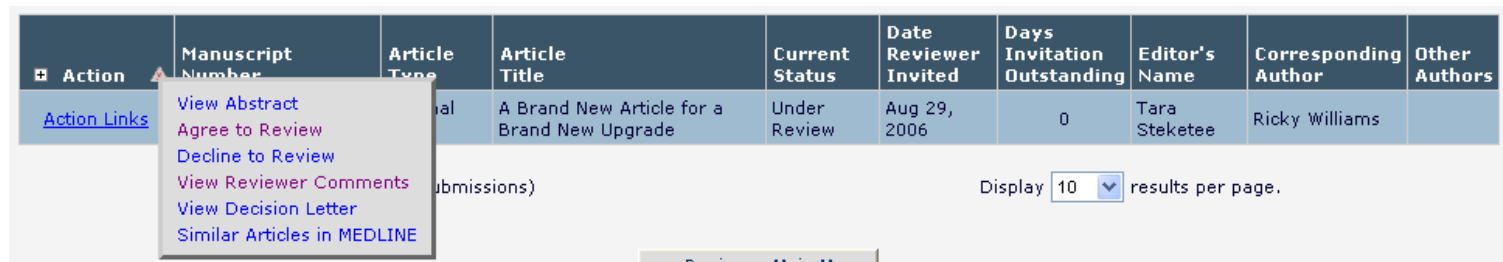

$\ll<$ Reviewer Main Menu

Click on View Reviewer Comments. A pop-up box will appear with a link to the Author's Response to the Reviewers' comments: 


\section{LWW Editorial Manager ${ }^{\circledR}$ - Tutorial for Reviewers}

View Reviewer Comments for Manuscript

TARATEST50-D-06-00010R1

"A Brand New Article for a Brand New Upgrade"

Click the Reviewer recommendation term to view the Reviewer comments.

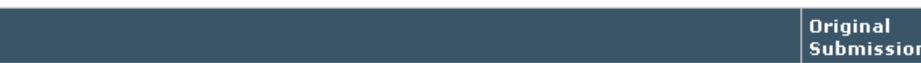

(Reviewer 1)

Ethel Merman (Reviewer 2)

Author Decision Letter

Major Revision

Minor Revision

$\underline{\text { Revise }}$

Author

Response to Reviewers

Click on this link, and the Author's response to all of the reviewer comments will be listed:

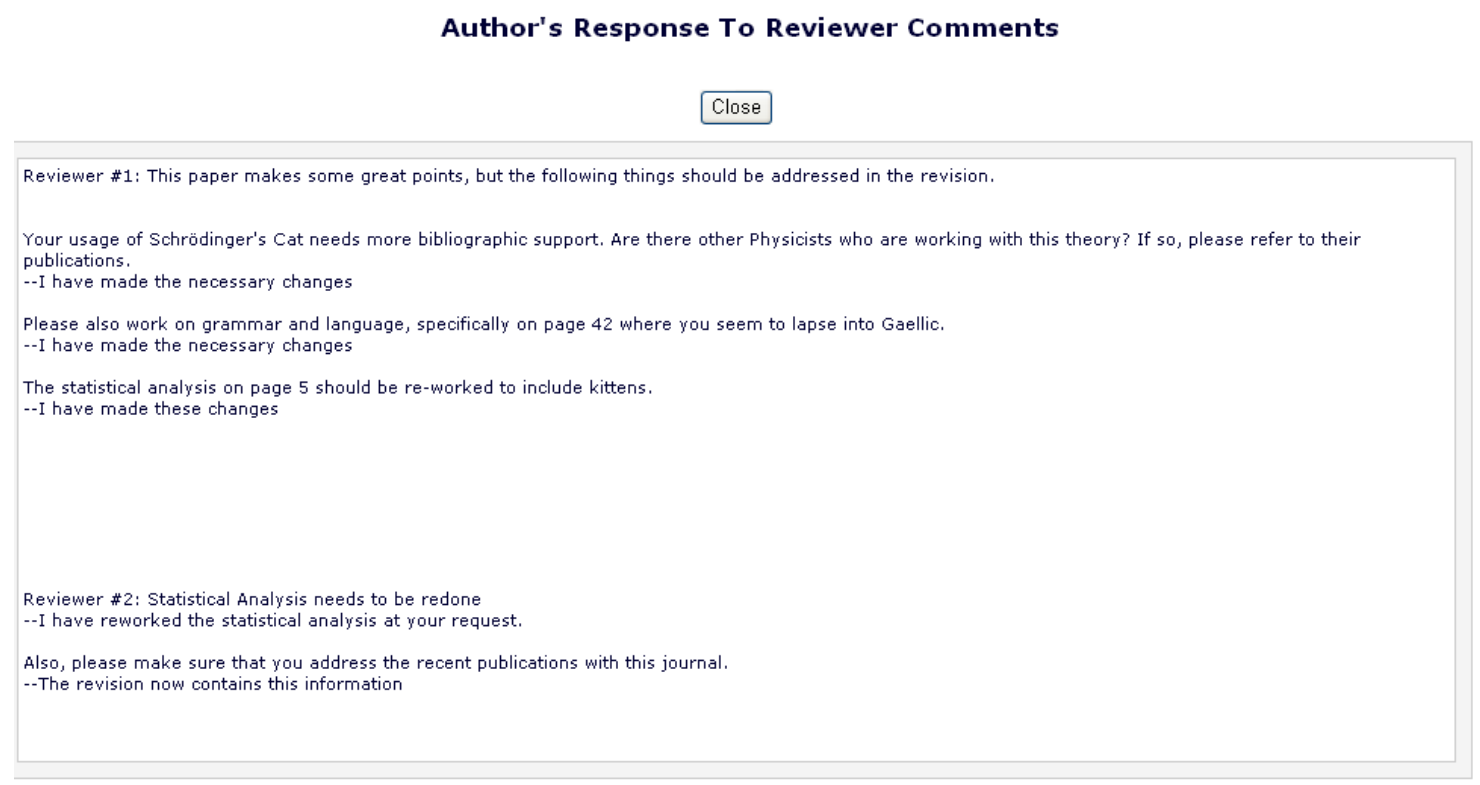

\section{Need more help submitting Reviews to Editorial Manager? \\ Read the LWW Guide for Reviewers}

\section{Search the Online Knowledge Base}

